化学還元法による (Fe, Co, Ni)-B 系非晶質超微粒子の作製とその焼結体の諸特性

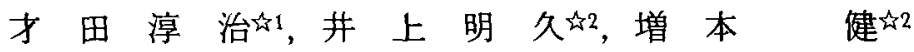 \\ 的1日新製龬制鉄鈵研究所表面処理研究部，广592 堺市石津西町5. \\ 的東北大学金属材料研究所, 今980 仙台市青葉区片平2-1-1.
}

\title{
Preparation of Amorphous Ultra-Fine Powders in (Fe, Co, Ni)-B Systems by a Chemical Reduction Method and Properties of Their Sintered Products
}

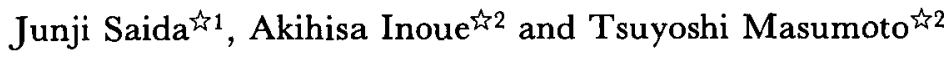 \\ 41 Steel R\&D Laboratory, Surface Treatment Department, Nisshin Steel Co. Ltd., 5 Ishizunishimachi Sakai 592. \\ (2) Institute for Materials Research, Tohoku University, 2-1-1 Katahira Aoba-ku Sendai 980.
}

Received July 25, 1991

\begin{abstract}
Amorphous ultra-fine powders in $(\mathrm{Fe}, \mathrm{Co}, \mathrm{Ni})-\mathrm{B}$ systems were prepared by a chemical reduction method using $\mathrm{KBH}_{4}$. The powders have a spherical morphology with diameters ranging from 20 to 50 $\mathrm{nm}$. The boron concentration is in the range of 25 to 35 at.\% and chemical composition of the metal elements can be controlled by changing the concentration of metal ions. Crystallization temperature $\left(T_{x}\right)$ and heat of crystallization for an ultra-fine $\mathrm{Fe}_{50} \mathrm{Ni}_{22} \mathrm{~B}_{28}$ powder agree with those obtained for the amorphous alloy with the same composition prepared by melt spinning. The reaction process consists mainly of the process of preparing $\mathrm{Me}_{2} \mathrm{~B}$ and $\mathrm{Me}(\mathrm{Me}=\mathrm{Fe}, \mathrm{Co}, \mathrm{Ni}$ ). Furthermore, the amorphous powders were found to be consolidated to a fully dense amorphous bulk by uniaxial pressing at temperatures below $T_{x}$. Their densities are almost equal to those of the corresponding arc-melted crystalline powders. Hardness values of the hot-pressed compacts are considerably lower than those of the melt-spun amorphous ribbons with the same composition.
\end{abstract}

\section{1 緒言}

非晶質合金は、通常、液体急冷法、気相急冷法、固体反 応法によって得ることができる。最近これらの方法とは、 非晶兵相の生成機構を異にすると考えられる化学反応法に より非晶質相が作製されることが見い出されだー3)。この 方法による非晶質相の生成は、ガラス遷移温度 $\left(\mathrm{T}_{8}\right)$ 以下 で起こるため、物質の虽点 $\left(\mathrm{T}_{\mathrm{m}}\right)$ と $\mathrm{T}$, との美に影辢を受 けず、その生成機搆は液体急冷法とは大きく異なっている。 徉って、これまで非晶質化が困難であった系あるいは組成 においても非晶質相か狌成される可能性がある。また、本
方法で生成した非晶質相は、直径が 2 0-50nmの極めて 微細な超微粒子形態をむっており、この点からむ新規な応 用が期待される。本論文では、これらの非晶質超微粒子の 作製法と構恉、組成、形態、熱的安定性、反応ブロセス等 について述べるとともにその焼結体の特性についても報告 する。

\section{2 実跧方法}

$\mathrm{Fe}, \mathrm{Co}, \mathrm{Ni}$ の硫酸塩または塩化物の水溶液0.1mol /を水素化ホウ素カリウム $\left(\mathrm{KBH}_{4}\right)$ の水溶液1mol/1 に 
混合させた。約 600 秒間混合後、析出した黒色生成物を 瀘過して、蒸留水とアセトンて洗浄した後空気中で乾焻さ せた。なお反応は室温で行なった。生成相の同定はX線回 折を用い、形態は走查電子顕微鏡（SEM）および透過電 子頙政鏡 (TEM) で観察した。析出物の組成は誘導結合 プラズマ ( I C P) 発光分析で決定した。熱的安定性は、 示差走查熱量計 (D S C) を用いて、0.33K/sの昇温速 度で測定した。このようにして作製した非晶質超微粒子を ホットプレスにより加焼結した。プレス時の温度はD S Cで測定した結晶化開始温度 $\left(\mathrm{T}_{\mathrm{x}}\right)$ の90-95\%を標潐

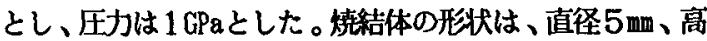
さ2ー3mm である。焼結体の組織は光学顕微鏡て観察し、 構造はX線回折で調べた。硬度はビッカース微小硬度計を 用いて2008の荷重で、また密度はトルエンを用いたア ルキメデス法により貺定した。

\section{3 実験結果および考察}

\section{3-1 構造、組成、形態、熱的安定性}

Fig.1は ( $\mathrm{Fe}, \mathrm{Co}, \mathrm{Ni})-\mathrm{B} 2$ 元および3元合金の 析出粒子のX線回折図形を示している。図中に示した化学 組成は I C Pで決定したすのである。いずれの合金におい ても結晶相の存在を示す回折ピークは観察されない。 Photo. 1はF e - C o-B合金㸮末のS EM写真を示してい

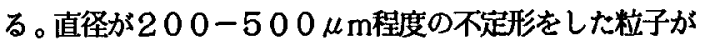
㓋察されるが、それらはさらに微練な粒子から構成されて いることがわかる。そこで、同じ合金粉末についてTEM を用いてより詳細に粒径と形態を調べた結果をPhoto. 2 に

Table 1. Mixing composition of metal ions in an aqueous solution, analyzed compositions of the chemically synthesized ( $\mathrm{Fe}, \mathrm{Co}, \mathrm{Ni}$ ) $-\mathrm{B}$ powders, and their crystallization temperature $\left(\mathrm{T}_{\mathrm{x}}\right)$ measured at a scanning rate of $0.33 \mathrm{~K} / \mathrm{s}$ by DSC.

\begin{tabular}{|c|c|c|c|}
\hline Alloy & $\begin{array}{c}\begin{array}{c}\text { Mixing comp } \\
(\mathrm{a}: \%)\end{array} \\
\end{array}$ & $\begin{array}{c}\text { Chemical comp. } \\
(\text { al } \%)\end{array}$ & $\begin{array}{l}\text { Crystallization } \\
\text { temp. } T_{x}(k)\end{array}$ \\
\hline $\mathrm{Fe}-\mathrm{B}$ & $\mathrm{Fe}_{100}$ & $\mathrm{Fe}_{61.9} \mathrm{~B}_{35.1}$ & 737 \\
\hline $\mathrm{CO}-\mathrm{B}$ & $\mathrm{CO}_{100}$ & $\mathrm{Co}_{64,4,4} \mathrm{~B}_{35.6}$ & 755 \\
\hline $\mathrm{Ni}-\mathrm{B}$ & $\mathrm{Ni}, 100$ & $\mathrm{Ni}_{70.2} \mathrm{~B} 29.8$ & 593 \\
\hline $\mathrm{Fe}-\mathrm{CO}-\mathrm{B}$ & $\mathrm{Fe}_{70} \mathrm{CO}_{30}$ & $\mathrm{Fe}_{1,5,6} \mathrm{Co}_{17,9} \mathrm{~B}_{36.5}$ & 719 \\
\hline $\mathrm{Fe}-\mathrm{Co}-\mathrm{B}$ & $\mathrm{Fe}_{30} \mathrm{Co}_{70}$ & $\mathrm{Fe}_{18.4} \mathrm{CO}_{4.7 .7} \mathrm{~B}_{39.9}$ & 735 \\
\hline $\mathrm{Fe}-\mathrm{Ni}-\mathrm{B}$ & $\mathrm{Fe}_{70} \mathrm{Ni}_{30}$ & $\mathrm{Fe}_{50.5} \mathrm{Ni}_{21.8} \mathrm{~B}_{27.7}$ & 709 \\
\hline $\mathrm{Fe}-\mathrm{Ni}-\mathrm{B}$ & $\mathrm{Fe}_{30} \mathrm{Ni}_{70}$ & $\mathrm{Fe}_{22.7} \mathrm{Ni}_{52.8} \mathrm{~B}_{24.5}$ & 621 \\
\hline $\mathrm{CO}-\mathrm{Ni}-\mathrm{B}$ & $\mathrm{Co}_{70} \mathrm{Ni}_{30}$ & $\mathrm{Co}_{4,6.5} \mathrm{Niz}_{20.6} \mathrm{~B}_{32.9}$ & 627 \\
\hline $\mathrm{CO}-\mathrm{Ni}-\mathrm{B}$ & $\mathrm{CO}_{30} \mathrm{Ni}_{70}$ & $\mathrm{CO}_{20.1} \mathrm{Ni}_{1,0.9} \mathrm{~B}_{33.0}$ & 625 \\
\hline
\end{tabular}

示す。これらの粉末は20ー50n粒经の極めて微細な粒 子から構成されていることがわかる。また電子線回折図形 は非晶質相特有のハローリングを示しており、本合金粉末 は非晶質超铔粒子であると言える。

Table1に種々の合金系について、金属イオンの混合比と析 出粒子中の組成およひ結晶化開始温度をまとめている。析 出粒子中の金属成分はほぼ金属イオンの混合比に比例して 変化しているが、B濃度はほば一定である。このように析 出粒子中の金属成分は、ほほ任意に制御できる。また結晶 化開始温度は同組成の液体急冷材とほぼ同じ值を示してい る。

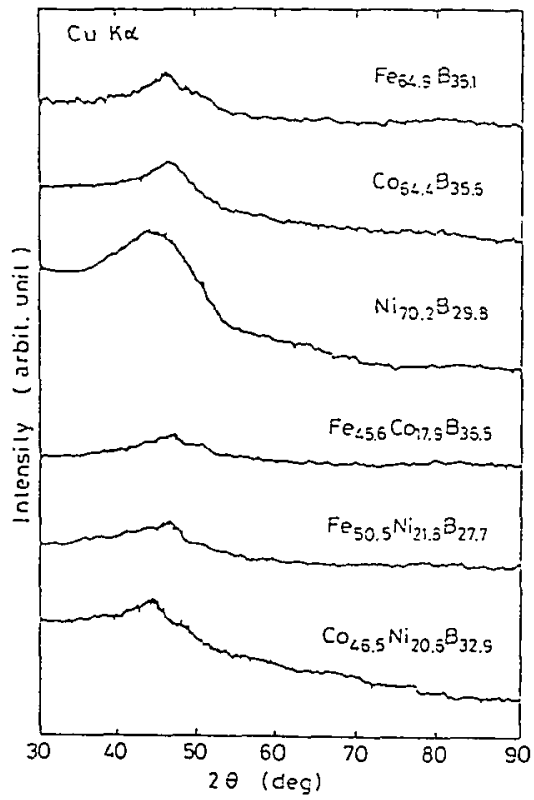

Fig. 1. X-ray diffraction patterns of (Fe,Co, Ni)-B powders prepared by chemical reduction.

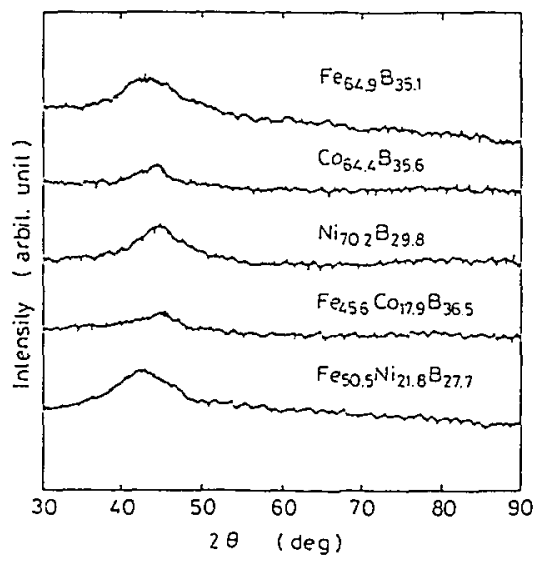

Fig.2. X-ray diffraction patterns of hot-pressed (Fe, Co, Ni)-B compacts. 


\section{3-2 反応プロセス}

現在の化学還元法の反応プロセスの詳細については明ら かでない。しかし、この方法と同様の反応を持つと考えら れている水素化ホウ素化物を用いた無電解めっきの反応式 4)などから次のような反応プロセスが考えられる5゙。

(1) $4 \mathrm{Me}^{2+}+2 \mathrm{BH}_{4}^{-}+6 \mathrm{OH}^{-}$

$$
\rightarrow 2 \mathrm{Me}_{2} \mathrm{~B}+6 \mathrm{H}_{2} \mathrm{O}+\mathrm{H}_{2}
$$

(2) $4 \mathrm{Me}^{2+}+\mathrm{BH}_{4}^{-}+8 \mathrm{OH}^{-}$

$$
\rightarrow 4 \mathrm{Me}+\mathrm{BO}_{2}^{-}+6 \mathrm{H}_{2} \mathrm{O}
$$

$$
(\mathrm{Me}=\mathrm{Fe}, \mathrm{Co}, \mathrm{Ni})
$$

（1）式が主反応であり、生成物の $\mathrm{Me}_{2} \mathrm{~B}$ が非晶質相を形 成すると考えられる。これは本方法で用いた非晶質超微粒 子が2 5-35at.\%のB濃度を有している結果とむ一致し ている。一方、反応式 (2) は結晶質の金属とホウ酸塩な どの不純物を生成するプロセスである。

\section{3-3 焼結体の諸特性}

Fig.2は、（ $\mathrm{F} \mathrm{e}, \mathrm{Co}, \mathrm{N}$ i ）－B系非晶質超微粒子か ら得た焼結体のX線回折図形を示している。焼結は $\mathrm{T} \times$ の 90-95\%、すなわち、T×より20-30K低い温度域 でおこなっている。この条件では、いずれの焼結体におい ても結晶相の回折ピークは見られず、非晶質相を保持して いることを示している。Photo.3は、C o-B系焼結体の断 面の未エッチング状態の光学顕微鏡写真である。未焼結領 域を示すコントラストや空吵は認められず、かなり高密度 な組織が形成されている。Table2は焼結体の $\mathrm{T}$ 、、結晶化の 発熱量 $\Delta H_{x}$ 、硬度、密度、充媜率をまとめたあのである。 比較材として、結晶化挙動については超微粒子を、硬度に ついては同組成の液体急冷材の結果を示している。結晶化 挙動は比較材とほぼ同じであり、非晶質性を維持した状態 て焼結が行われていることを表わしている。一方、硬度は 液体急冷材のほぼ半分の值である。これは非晶質超微粒子 の表面の酸化膜のため粒子同志の真の結合か阻害されてい るためと考えられる。充填率は、アーク溶解で得たバルク 材と同等の值を示している。しかし、密度の絶対值は液体 急冷材のそれと比べるとかなり低くなっている。これは、 非晶質超微粒子中に含有されているホウ酸塩や酸化物など の不純物の影響であると考えられる。いずれにしてあ、高 い充填率をむつ焼結体か得られることから、この非晶質超 微粒子は高密度非晶質焼結体を作製するための素材として 有用であると考えられる。

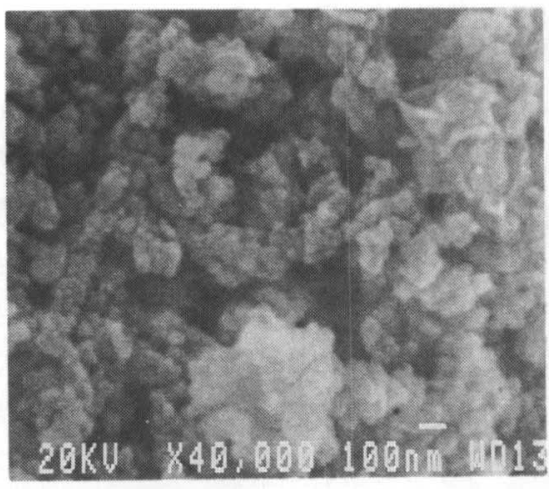

Photo.1. Scanning electron micrograph revealing the shape and morphology of $\mathrm{Fe}_{45}{ }_{6 .} \mathrm{Co}_{17.9} \mathrm{~B}_{36.5}$ powder prepared by chemical reduction.

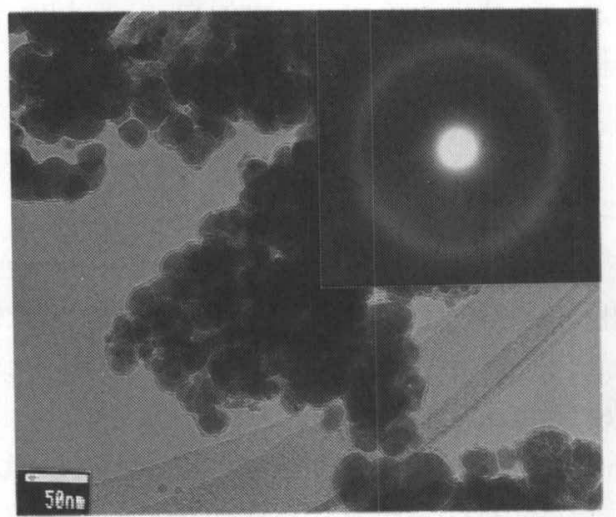

Photo.2. Bright-field electron image and selected area diffraction pattern of $\mathrm{Fe}_{45.6} \mathrm{CO}_{17.9^{-}}$ $B_{36.5}$ powder.

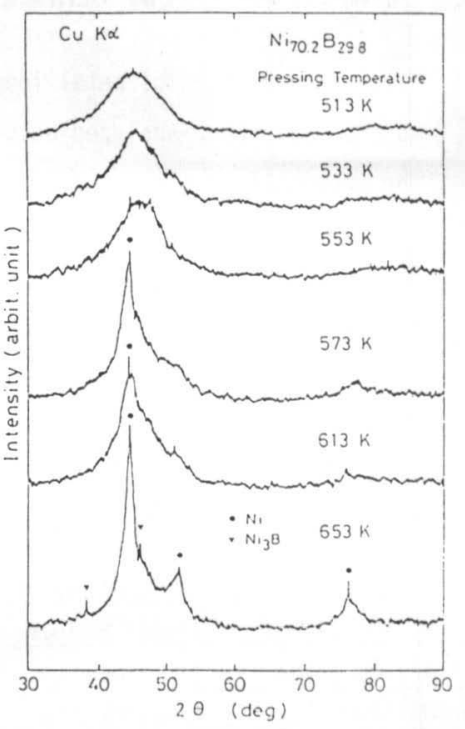

Fig.3. X-ray diffraction patterns of $\mathrm{Ni}_{70}{ }_{2} \mathrm{~B}_{29.8}$ compacts prepared by hot pressing at various temperatures. 
Table 2. Vickers hardness, packing factor, density and thermal stability of hot-pressed compacts made from $(\mathrm{Fe}, \mathrm{Co}, \mathrm{Ni})-\mathrm{B}$ amorphous powders. The data for the ultra-fine amorphous powders and melt-spun amorphous ribbons are also shown for comparison.

\begin{tabular}{|c|c|c|c|c|c|c|c|}
\hline \multicolumn{3}{|c|}{ A 110 y $\left(\begin{array}{lll}\text { a } & \text { t. } \%)\end{array}\right)$} & $\mathrm{Fe}_{64.0 \mathrm{~B}_{35.1}}$ & $\mathrm{CO}_{64,4 B_{35.8}}$ & $\mathrm{Ni}_{70.2} \mathrm{~B}_{20.8}$ & $\mathrm{Fe}_{45.8} \mathrm{CO}_{17.0 \mathrm{~B}_{30}}$ & 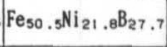 \\
\hline \multirow{2}{*}{ Poxder } & \multicolumn{2}{|c|}{$T \times(K)$} & 737 & 755 & 593 & 710 & 709 \\
\hline & \multicolumn{2}{|c|}{$\Delta \mathrm{H} \times(\mathrm{J} / \mathrm{g})$} & 146.9 & 107.9 & 185.6 & 158.8 & 178.0 \\
\hline \multirow{2}{*}{$\mathrm{B} \cup \mathrm{K}$} & \multicolumn{2}{|c|}{$T \times(K)$} & 729 & 732 & 589 & 720 & 715 \\
\hline & \multicolumn{2}{|c|}{$\Delta \mathrm{H} \times(\mathrm{J} / \mathrm{g})$} & 145.8 & 93.3 & 134.8 & 131.5 & 158.0 \\
\hline \multirow{2}{*}{\multicolumn{2}{|c|}{$\begin{array}{l}\text { Yickers } \\
\text { Hardness } \\
\text { Nuaber }\end{array}$}} & Bulk & 592 & 736 & 416 & 672 & 550 \\
\hline & & Ribbon & 1419 & 1352 & 1027 & 1213 & 1034 \\
\hline \multicolumn{3}{|c|}{ Density $\left(\mathrm{X}_{8} / \mathrm{a}^{3}\right)$} & 5. 25 & 6. 04 & 5. 88 & 5. 68 & 4. 84 \\
\hline \multicolumn{3}{|c|}{ Packing Factor $(\%)$} & 87.7 & 94.0 & 99.8 & 99.8 & 95.3 \\
\hline
\end{tabular}

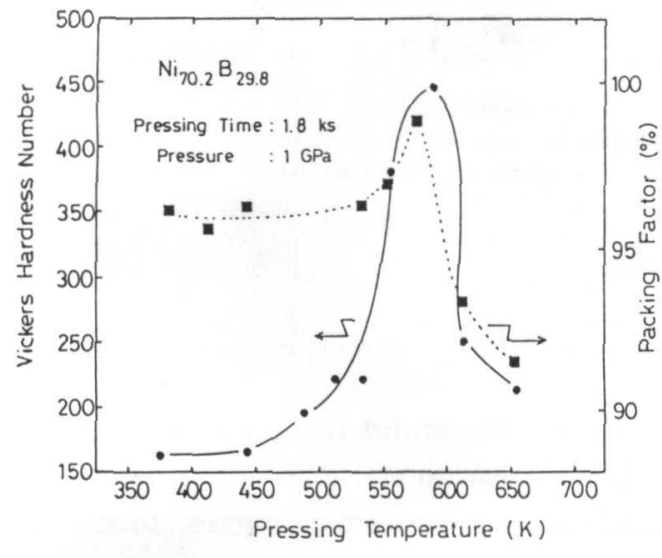

Fig.4. Changes in the Vickers hardness number and packing factor of hot-pressed $\mathrm{Ni}_{70.2} \mathrm{~B}_{29.8}$ compacts with pressing temperature.

\section{3-4 焼結温度の影響}

Fig.3はN i -B系粉末から得た焼結材のX線回折図形の 焼結温度による変化を表わしている。この非晶質超微粒子 のD S Cで測定した結晶化開始温度は593Kであった。 焼結体のX線回折結果むこれとほぼ一致しており、573 K以上の焼結温度で結晶質のN i と $\mathrm{N}$ i 3 Bが析出している。 Fig.4は同じ焼結材の硬度および充媜率の焼結温度による变 化を示している。硬度は結晶相の析出のごく初期において 大きく上昇し、析出完了後急速に減少する。また充媜率む 硬度と同様に $\mathrm{T} \times$ 直下で最大值を示す。これらの結果から、 $\mathrm{T}_{\mathrm{x}}$ 直下の焼結温度を選ぶことによって、大きな硬度と充 買率をすつ非晶質焼結体を作製できることが明らかとなっ た。

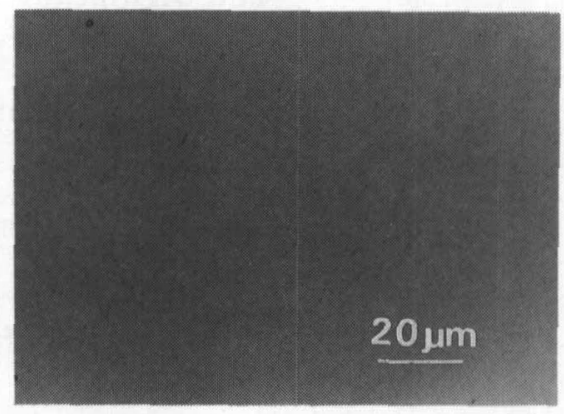

Photo.3. Optical micrograph of hot-pressed $\mathrm{C}_{64,4^{-}}$ B35.6 compact.

\section{4 まとめ}

水素化ホウ素カリウム $\left(\mathrm{KBH}_{4}\right)$ を用いた化学還元法に より ( $\mathrm{Fe}, \mathrm{Co}, \mathrm{Ni})$ - B 系非晶質超微粒子を作製す ることができた。また、ホットプレスによりこれらの非晶 質超微粒子を $\mathrm{T} \times$ 以下の温度て焼結することができた。しか しながら、焼結体の硬度は同組成の液体急冷材の約半分で あった。これは酸化膜や不純物のため粒子間の真の結合が 阻害されているだめであると考元られる。硬度と充媜率は 焼結温度がT×直下で最大値を示し、より高温域での結晶相 の析出に伴い大きく低下する。

\section{文献}

1) J. van Wonterghem, S. Morup, C.J.W. Koch, S.W. Charles and S. Wells: Nature,322(1986), 622.

2) I. Dragieva, M. Slavcheva and D. Buchkov:J.JessCommon Met., 117(1986), 311.

3) A. Inoue, J. Saida and T. Masumoto:Met. Trans., $19 A(1988), 2315$.

4) H. Narcus:Plating, 54(1967), 380.

5) J. Saida, A. Inoue and T. Masumoto:Met. Trans., 22A(1991), №.7, 印刷中. 